\title{
Video Article \\ Distinctive Capillary Action by Micro-channels in Bone-like Templates can Enhance Recruitment of Cells for Restoration of Large Bony Defect
}

\author{
Daniel S. Oh ${ }^{1}$, Alia Koch ${ }^{1}$, Sidney Eisig ${ }^{1}$, Sahng Gyoon Kim ${ }^{2}$, Yoon Hyuk Kim ${ }^{3}$, Do-Gyoon Kim ${ }^{4}$, Jae Hyuck Shim ${ }^{5}$ \\ ${ }^{1}$ Oral and Maxillofacial Surgery, Columbia University \\ ${ }^{2}$ Endodontics, Columbia University \\ ${ }^{3}$ Mechanical Engineering, Kyung Hee University, South Korea \\ ${ }^{4}$ Orthodontics, The Ohio State University \\ ${ }^{5}$ Pathology, Weill Cornell Medical College
}

Correspondence to: Daniel S. Oh at dso2113@cumc.columbia.edu

URL: https://www.jove.com/video/52947

DOI: doi:10.3791/52947

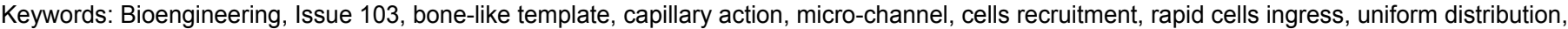
cells inhabitation, cells retention, bone reconstruction, critical bony defect

Date Published: 9/11/2015

Citation: Oh, D.S., Koch, A., Eisig, S., Kim, S.G., Kim, Y.H., Kim, D.G., Shim, J.H. Distinctive Capillary Action by Micro-channels in Bone-like Templates can Enhance Recruitment of Cells for Restoration of Large Bony Defect. J. Vis. Exp. (103), e52947, doi:10.3791/52947 (2015).

\section{Abstract}

Without an active, thriving cell population that is well-distributed and stably anchored to the inserted template, exceptional bone regeneration does not occur. With conventional templates, the absence of internal micro-channels results in the lack of cell infiltration, distribution, and inhabitance deep inside the templates. Hence, a highly porous and uniformly interconnected trabecular-bone-like template with micro-channels (biogenic microenvironment template; BMT) has been developed to address these obstacles. The novel BMT was created by innovative concepts (capillary action) and fabricated with a sponge-template coating technique. The BMT consists of several structural components: interconnected primary-pores $(300-400 \mu \mathrm{m})$ that mimic pores in trabecular bone, micro-channels $(25-70 \mu \mathrm{m})$ within each trabecula, and nanopores $(100-400 \mathrm{~nm})$ on the surface to allow cells to anchor. Moreover, the BMT has been documented by mechanical test study to have similar mechanical strength properties to those of human trabecular bone $(\sim 3.8 \mathrm{MPa})^{12}$.

The BMT exhibited high absorption, retention, and habitation of cells throughout the bridge-shaped $(\Pi)$ templates $(3 \mathrm{~cm}$ height and $4 \mathrm{~cm}$ length). The cells that were initially seeded into one end of the templates immediately mobilized to the other end $(10 \mathrm{~cm}$ distance) by capillary action of the BMT on the cell media. After $4 \mathrm{hr}$, the cells homogenously occupied the entire BMT and exhibited normal cellular behavior. The capillary action accounted for the infiltration of the cells suspended in the media and the distribution (active migration) throughout the BMT. Having observed these capabilities of the BMT, we project that BMTs will absorb bone marrow cells, growth factors, and nutrients from the periphery under physiological conditions.

The BMT may resolve current limitations via rapid infiltration, homogenous distribution and inhabitance of cells in large, volumetric templates to repair massive skeletal defects.

\section{Video Link}

The video component of this article can be found at https://www.jove.com/video/52947/

\section{Introduction}

The ultimate goal of bone tissue engineering with synthetic constructs is the incorporation of the constructs into the host bone, repopulation of the constructs with host cells, and reconstitution of gas and body fluid exchanges to restore normal bone function. Considerable research has been reported over the last decade in the use of polymeric and ceramic biomaterials for producing scaffolds ${ }^{1,2}$. However, the ideal material and fabrication technique for optimal bone tissue regeneration has yet to be identified. In addition, there is an overall lack of success in bringing these technologies to the clinic, especially for the reconstruction and restoration of large bone defects. Therefore, restoring critical sized bony defects still remains a clinical challenge ${ }^{1-5}$.

Ideally, the scaffolds for bone tissue regeneration should exhibit biocompatibility without causing inflammatory responses or foreign body/toxic reactions, have closely matched mechanical properties when compared to those of native bone, and possess a mechanism to allow diffusion and/or transport of ions and nutrients. Strong bonding with the host bone, dynamic bone growth, vascular ingrowth, and biodegradation of the scaffolds are equally desirable. Although the use of biodegradable polymer scaffolds has exhibited progress in terms of tissue ingrowth, there are controversies over their use for bone regeneration.

Notwithstanding these extensive efforts, the highly organized structural synthetic constructs still have limited potential in overcoming the obstacle of passive cell penetration. Most of these approaches have resulted in the in vitro tissue ingrowth with cross-sections of less than a few $\mu \mathrm{m}$ to several $\mathrm{mm}$ from the external surface, an incomplete integration with host bone, and only partial bone regeneration in vivo ${ }^{6,7}$. The pioneering 
cells do not migrate deeply into the constructs because of the lack of an initial force that pulls them inside before cell colonization begins. Consequently, cell colonization strictly occurs at the scaffold periphery, becoming an obstruction from the periphery to the center of the scaffold. Thus, the diffusion of oxygen and nutrients into the inner parts of the templates becomes limited ${ }^{8}$. Therefore, it is clear that the architecture of the scaffolds (pore size, porosity, interconnectivity, and permeability) that affect the transport and diffusion of substances throughout the scaffolds is critical for achieving well-distributed cell proliferation and differentiation ${ }^{9,10}$. Although calcium phosphates have been used in the past for scaffold fabrication, different processes and procedures have often resulted in calcium phosphate scaffolds with varying architectures. Thus, the selection of the manufacturing process becomes important in dictating the scaffold architecture needed for successful bone tissue regeneration.

In conclusion, there are still two major shortcomings of bone tissue engineering that need to be addressed: the initial cell recruitment into the template prior to cell attachment and colonization and the quality of substance flow both into and out of the template.

\section{Polyurethane (PU) Sponge Preparation as Template}

1. Use PU sponges to produce hydroxyapatite templates containing interconnecting pores. Use each sponge to provide the primary trabeculae for the formation of the template struts as well as the formation of micro-channels within the trabeculae.

2. Cut and trim $80 \mathrm{ppi}$ (pores per inch) sponges into 2 bridge-shapes with dimensions of $3.5 \mathrm{~cm}$ in height $\times 5 \mathrm{~cm}$ in length $\times 1.5 \mathrm{~cm}$ in width. Note: The dimensions and shapes can be chosen according to the desired primary pore size: $100 \mathrm{ppi}, 80 \mathrm{ppi}$, and $60 \mathrm{ppi}$.

3. Make a $100 \mathrm{ml}$ of $4 \%(\mathrm{w} / \mathrm{v}) \mathrm{NaOH}$ solution using a $150 \mathrm{ml}$ beaker; then immerse and squeeze until the prepared sponges are completely soaked.

4. After soaking, place the beaker with the sponges in the ultrasonicator $(42 \mathrm{kHz})$.

5. Ultrasonically pre-treat the PU sponges for 15-20 min without heat to modify the surface properties.

6. Rinse with distilled water for 5-10 min. While rinsing, squeeze the sponges and allow them to expand 5 to 7 times in order to remove the residual $\mathrm{NaOH}$ inside the sponges.

7. Squeeze the sponges with paper towels in order to remove excess water; then dry them in an oven at $60-80^{\circ} \mathrm{C}$.

\section{Hydroxyapatite (HA) Slurry Preparation for Coating}

1. Before making the HA slurry, measure the weight of a beaker with a magnetic stir bar. This measurement will be used to calculate the powder/liquid ratio.

2. Measure $10 \mathrm{~g}$ of the nano-sized HA powder.

3. Add $20 \mathrm{ml}$ of distilled water into the $50 \mathrm{ml}$ beaker. Heat for $120-140{ }^{\circ} \mathrm{C}$ and stir using a hot plate magnetic stirrer.

4. Add $0.3 \mathrm{~g}(3 \% \mathrm{w} / \mathrm{w})$ of polyvinyl alcohol (PVA) $(89,000-98,000 \mathrm{MW})$ per powder into distilled water while stirring at $300-400 \mathrm{rpm}$.

5. Stir until the PVA has completely dissolved. The solution should be clear after complete dissolution of the PVA.

6. Turn off the heat and add $0.1 \mathrm{~g}(1 \% \mathrm{w} / \mathrm{w})$ of sodium carboxymethyl cellulose $(\mathrm{CMC})$ (ultra-low viscosity) for powder while stirring at $400-500$ rpm. The solution should be clear after complete dissolution of the PVA.

7. Stir until the CMC has completely dissolved and cool down to RT.

8. Add $0.3 \mathrm{~g}(3 \% \mathrm{w} / \mathrm{w})$ of ammonium polyacrylate dispersant per powder while stirring at $300-400 \mathrm{rpm}$. Stir until completely dissolved.

9. Add $0.2 \mathrm{~g} \mathrm{(2 \%} \mathrm{w} / \mathrm{w})$ of glycerin per powder while stirring at $300-400 \mathrm{rpm}$. Stir until completely dissolved.

10. Slowly disperse the HA powder into the solution while stirring at $600-900 \mathrm{rpm}$ and keep stirring for $5 \mathrm{~min}$.

11. Sonicate for 5 min using an ultrasonicator to ensure dispersion of any agglomeration of the HA powder.

12. Add an extra $5 \mathrm{ml}$ of distilled water into the mixture while stirring at $600-900 \mathrm{rpm}$ and heat at $90-100{ }^{\circ} \mathrm{C}$.

13. Keep stirring the mixture using a magnetic stirrer at $600-800 \mathrm{rpm}$ at $90-100^{\circ} \mathrm{C}$ in order to evaporate the water content.

14. Measure the whole weight including the beaker and mixture from time to time until a powder/liquid ratio of 1.75-1.8 is obtained.

15. Formatting the powder/liquid ratio, divide the weight of the powder by the total weight of the mixture (2.14), including the powder, reagents, and water, minus the weight of the beaker and stirrer (2.1), and minus the HA powder (2.2).

Note: For example: If A (entire mixture including powder, reagents, and water) is $49.05 \mathrm{~g}, \mathrm{~B}$ (beaker with stirrer) is $33.5 \mathrm{~g}$, and then $\mathrm{C}(\mathrm{HA}$ powder) is $10 \mathrm{~g}$.

$C /(A-B-C)=10 /(49.05-33.5-10)=1.80$

16. Allow the slurry to cool down to RT before using for coating.

\section{HA coating, Drying, and Sintering}

1. Coat the prepared PU sponges with the HA coating slurry using a stainless spatula until the slurry is homogenously distributed throughout the PU sponge onto a glass plate.

Note: After removing the excess slurry, some of pores may still be clogged with slurry because of the high slurry viscosity.

2. In order to ensure interconnectivity, uniformity, and open pores, slightly blow the HA coated templates using an air compressor. This process ensures that the templates are homogeneously coated both on the inside and outer surfaces of the PU sponge.

Note: If a homogeneous coating is not achieved, the HA coated templates will collapse during the sintering process and may also crack while handling due to low mechanical strength. Additionally, the homogeneous coating is critical in creating micro-channels within the trabeculae.

3. Dry the HA coated templates for a minimum of $5 \mathrm{hr}$ under cooling conditions $\left(20-25^{\circ} \mathrm{C}\right)$ with gentle air circulation. However, extend the drying time based on the size of template.

Note: After drying, the HA coated templates will typically shrink approximately $8 \%$ to $10 \%$ in each dimension.

4. After the drying process, place the HA coated templates on an alumina crucible. Then, place them in a high temperature furnace and use the following 8 step sintering profile.

1. Heat $2{ }^{\circ} \mathrm{C} / \mathrm{min}$ until $230^{\circ} \mathrm{C}$. 
2. Heat $1{ }^{\circ} \mathrm{C} / \mathrm{min}$ until $280^{\circ} \mathrm{C}$.

3. Heat $0.5^{\circ} \mathrm{C} / \mathrm{min}$ until $400^{\circ} \mathrm{C}$.

4. Heat $3{ }^{\circ} \mathrm{C} / \mathrm{min}$ until $600^{\circ} \mathrm{C}$. Keep at $600^{\circ} \mathrm{C}$ for $1 \mathrm{hr}$.

5. Heat $5^{\circ} \mathrm{C} / \min$ until $1230^{\circ} \mathrm{C}$. Keep $1,230^{\circ} \mathrm{C}$ for $3 \mathrm{hr}$.

6. Cool $5^{\circ} \mathrm{C} / \mathrm{min}$ to $\mathrm{RT}$.

Note: Sintering will further shrink the HA coated sponge templates by approximately $22 \%-25 \%$ in each dimension.

\section{Ingress and Inhabitancy of Cells into Template}

1. Culture pre-osteoblastic MC3T3 cells in a non-osteogenic media consisting of a-MEM, supplemented with $10 \%$ Fetal Bovine Serum (FBS) and $1 \%$ antibiotics (streptomycin and penicillin) at $37^{\circ} \mathrm{C}$ in a humidified atmosphere containing $5 \% \mathrm{CO}_{2}$.

2. Add $10 \mathrm{ml}$ of a cell suspension at $2 \times 10^{6}$ cell density into a single well within a 6 -well plate.

3. Place the $3 \mathrm{~cm} \times 4 \mathrm{~cm} \times 1 \mathrm{~cm}$ bridge-shaped template vertically into the 6 -well plate. Place one leg of the template into the plate containing the cell suspension, and the other leg into an adjacent empty well.

4. Allow the template to absorb the cell suspension for $10 \mathrm{~min}$.

5. Add $5 \mathrm{ml}$ of media thereafter to the well that was originally filled with the cell suspension.

6. Replenish the medium in both wells every 2 or 3 days until 7 days have elapsed.

7. Determine the efficacy of cell mobility by hematoxylin and eosin staining ${ }^{11}$.

1. Fix the cells and scaffold by immersing in $100 \% \mathrm{EtOH}$ for $20-30 \mathrm{~min}$.

2. Stain with Hematoxylin for 1-2 min.

3. Rinse with distilled water for 1-2 min for twice.

4. Dehydrate by immersion in $70 \%$, then $95 \%$, then $100 \%$ EtOH for $1-2$ min each.

5. Stain with Eosin for 20-30 sec.

6. Rinse with distilled water for 12 min for twice.

7. Dehydrate by immersion in $70 \%, 80 \%, 90 \%$, and $100 \%$ EtOH for $1-2$ min each.

8. Embed the scaffold in an acrylic resin for sectioning and imaging

8. Determine the cell viability with the 3-[4,5-Dimethylthiazol-2-yl]-2,5-diphenyl tetrazolium bromide (MTT) cell viability assay and Live/Dead assay (Live/dead cell staining kit MPTP) at time points of day 3 and $7^{11}$.

Note: The scheme of bone-like template fabrication protocols are represented in the "Representative Results" session.

\section{Representative Results}

The overall structure of the BMT exhibits a unique three-dimensional template with trabecular bone-like internal structures. The BMT contains macro-pores, micro-channels, and nano-pores. Clear configurations of fully interconnected macro-pores (average size of $320 \mu \mathrm{m}$ ), microchannels (average diameter of $50 \mu \mathrm{m}$ ), and nano-pores (average size of $100 \mathrm{~nm}$ ) were verified with a scanning electron microscope (EVO-40; ZEISS) as well as through micro-tomography.

Figure 1 shows stepwise detailed protocols in creating a BMT. Through precise control of the protocols from the preparation of the PU sponges to the sintering process (P1 - P7; Figure 1), the following features can be achieved: a highly dense and smooth surface after HA coating and drying; a precisely shaped and sized 3-D template; a fully interconnected porous trabecular network similar to that of trabecular bone; and micro-channels within each trabecula that mimic intra-osseous channels such as Haversian canals and Volkmann's canals (Figures 2 \& 3 ). Furthermore, relatively high mechanical strength $(\sim 3.8 \mathrm{MPa})$ similar to that of human trabecular bone was measured by a compressive strength test. Highly similar histomorphometric parameters with those of human lumbar vertebrae trabecular bone were confirmed by micro-CT analysis ${ }^{12}$. Different magnitudes of capillary action were demonstrated through different capillary diameters in Figure $\mathbf{4}$ using computational simulation. Through these simulations, we projected that the BMT would exhibit varying absorption rates within the primary-pores $(300-400 \mu \mathrm{m})$ and microchannels $(25-70 \mu \mathrm{m})$ based on the diameters. Smaller capillaries exhibited stronger absorption capacities. This assumption was verified in this experiment as shown in Figure 5.

The BMT exhibited highly effective fluid absorption and retention through the capillary action of the micro-channel structures; stevenel's blue stain was used as the fluid medium to easily track the flow (Figure 5). Based on computational simulation, the BMT with these configurations were seen to absorb and retain cell suspensions up to $8.5 \mathrm{~cm}$ in total distance within $10 \mathrm{sec}$. Due to a strong capillary action induced by the internal structures, the stained medium reached the opposite end of a $3 \mathrm{~cm}$ (height) $\times 4 \mathrm{~cm}$ (length) $\times 1 \mathrm{~cm}$ (width) bridge-shaped template within $1 \mathrm{~min}$ and $40 \mathrm{sec}$. Furthermore, active cell mobilization and incorporation into the BMT was observed (Figure 6). Subsequently, the homogenous cell mobilization and attachment resulted in enhanced proliferation and matrix formation in an evenly distributed formation. Moreover, longdistance $(\sim 10 \mathrm{~cm})$ migration of cells through the BMT was validated immediately after the BMT was saturated with the cell suspension. Seeded cells survived in the template segment that was exposed to the air and not immersed in the culture medium. In this experiment, the culture medium was provided to the cells by exclusively in the wells touching only the legs of the scaffold. The capillary action exhibited by the microchannels then allowed for fresh medium to reach the top, bridge portion of the scaffold. After 3 days of culture, the template became occupied with rapidly proliferating cells. After 7 days of culture, each trabecula was wrapped by extra cellular matrices and embedded with cells ${ }^{13}$. 


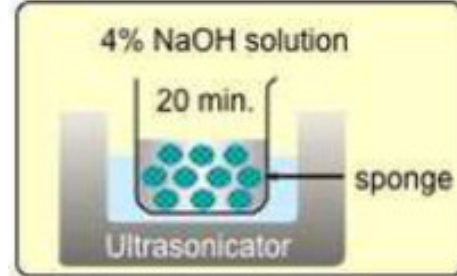

P1: Pre-treatment of PU sponges using ultrasonicator

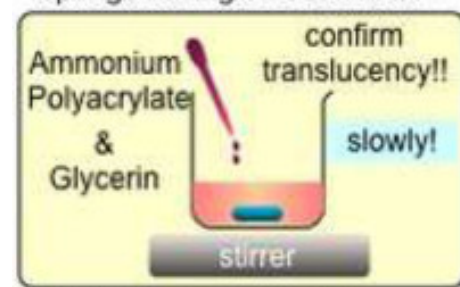

P4: Add dispersant while stirring then drying agent

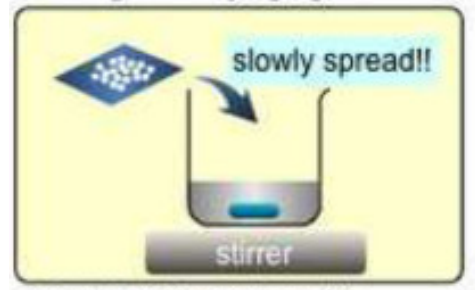

P5: Add HA powder while stirring and heat

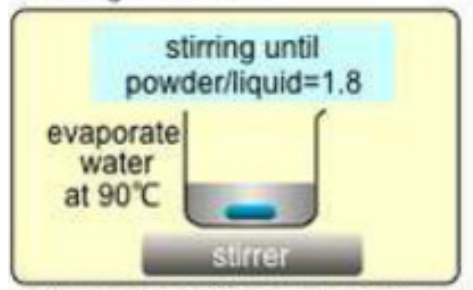

P6: Further stirring until powder/liquid

$=1.8$ then coating onto $\mathrm{PU}$ sponge

Figure 1. The overall bone-like template fabrication protocol from the pre-treatment of PU sponge (P1) to the final heat treatment (P7). Keeping the precise sintering profile after P7 is crucial in achieving favorable mechanical strength. Please click here to view a larger version of this figure.

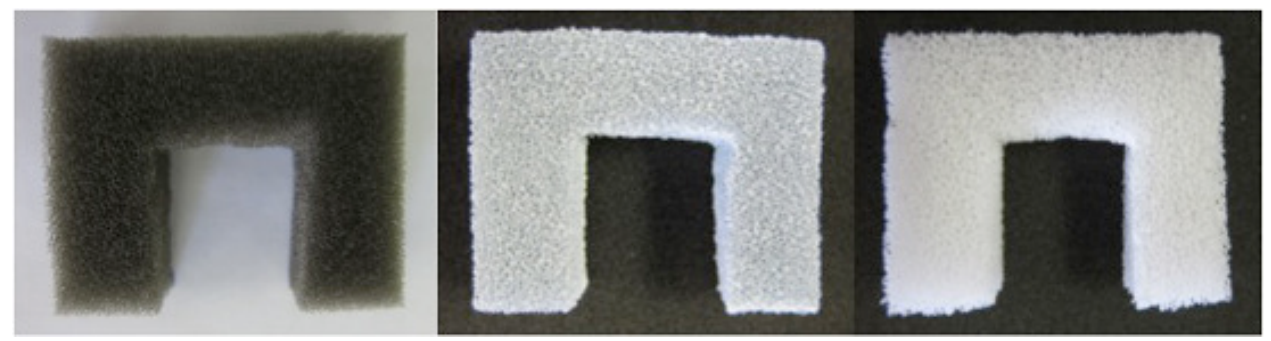

Figure 2. Representative stereo microscope (AmScope; SM-2TZ-M) images (x4) of a 80 ppi sized PU sponge (left), HA coated and dried BMT (middle), and sintered BMT (right). (Dimension: $3 \mathrm{~cm}$ in height $\times 4 \mathrm{~cm}$ in length $\times 1 \mathrm{~cm}$ in width). Please click here to view a larger version of this figure. 


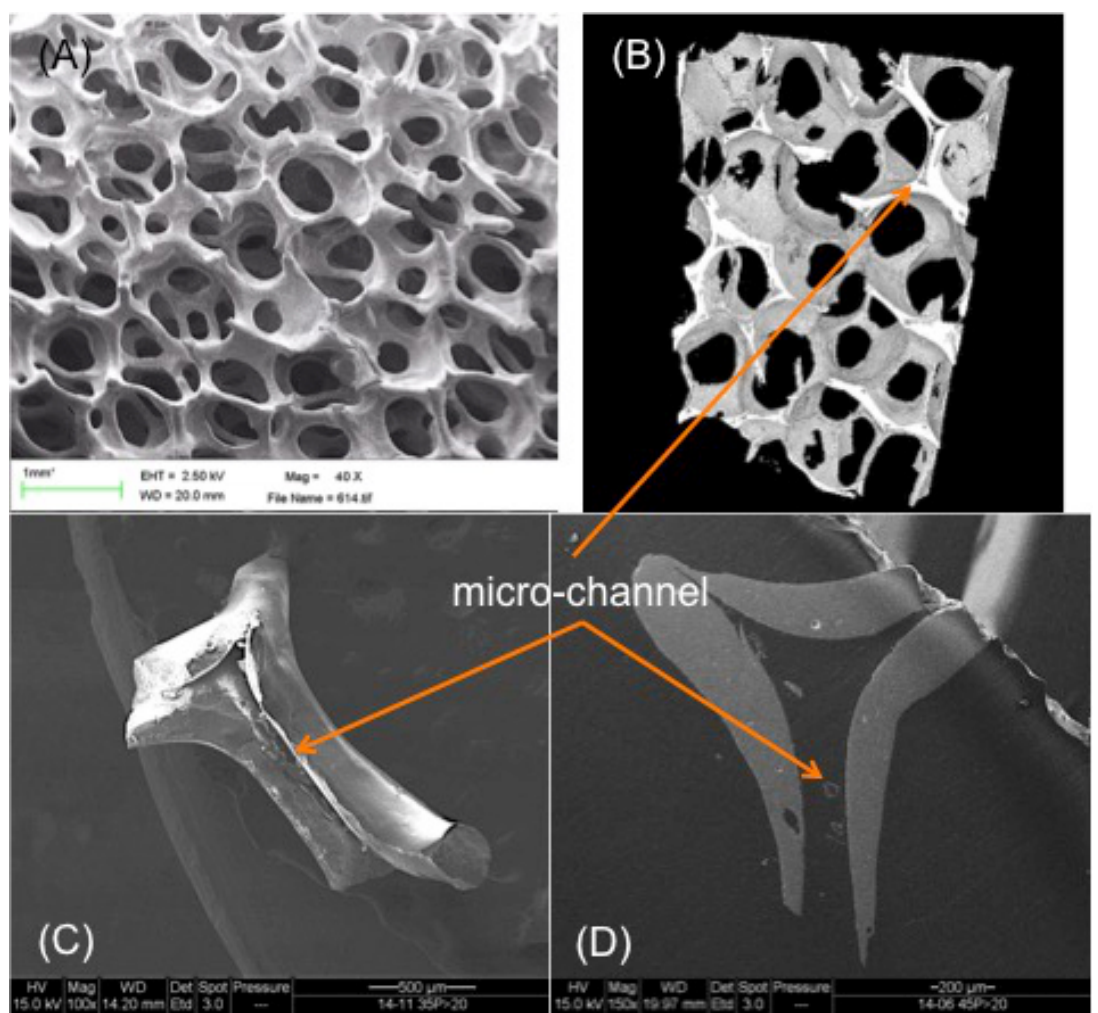

Figure 3. SEM and micro-CT images of a biogenic template: (A) an overall image of a biogenic template, (B, C, D) images for microchannels. In order to highlight clear micro-channels in the trabeculae, the template was granulated. Please click here to view a larger version of this figure.

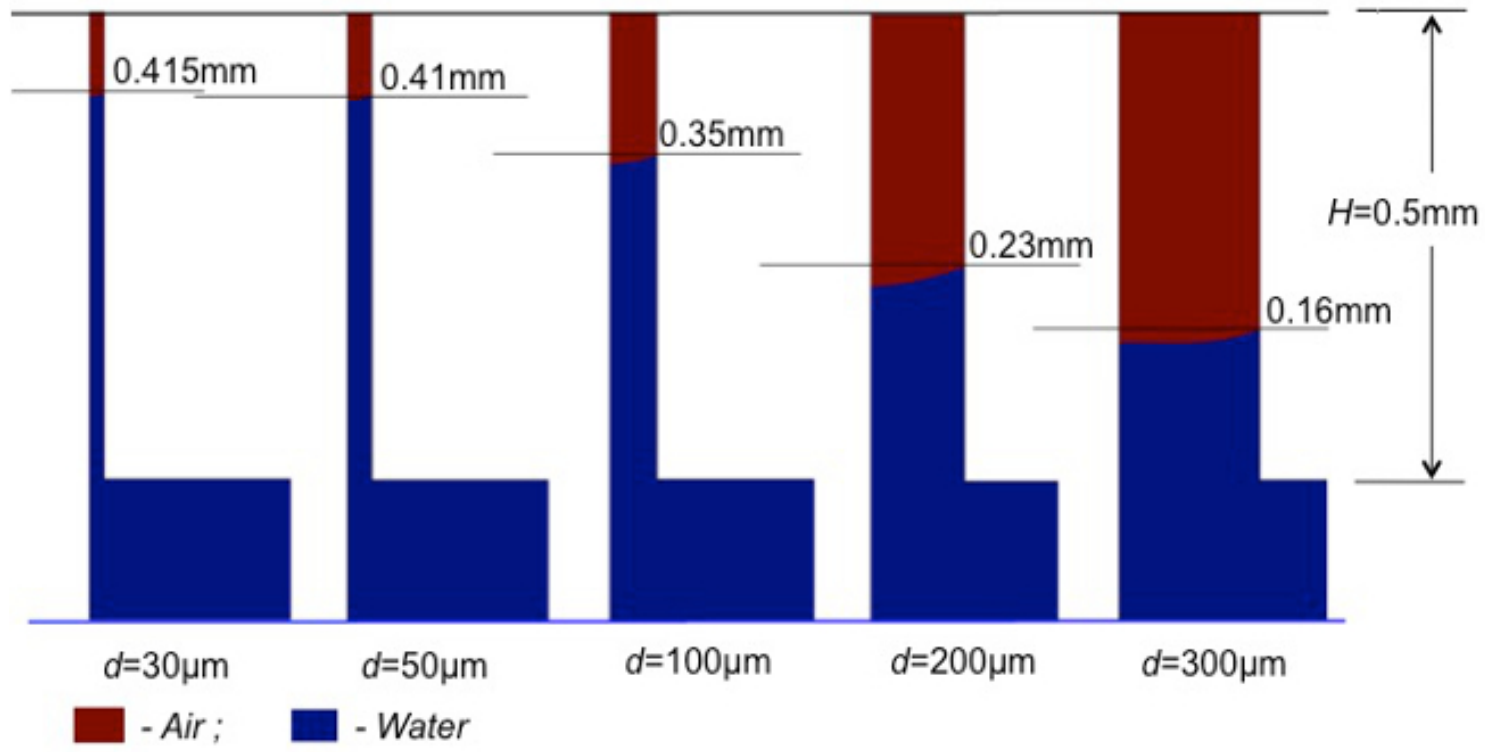

Figure 4. Computational calculation of capillary action with different channel diameters. Within the same time period (0.4 ms), while the largest capillary $(d=300 \mu \mathrm{m}$ : refers to primary-pore) absorbed the medium (blue) up to $0.16 \mathrm{~mm}$ in height, the smallest capillary $(\mathrm{d}=30 \mu \mathrm{m}$ : refers to micro-channel) absorbed the medium up to $0.415 \mathrm{~mm}$ in height. Please click here to view a larger version of this figure. 

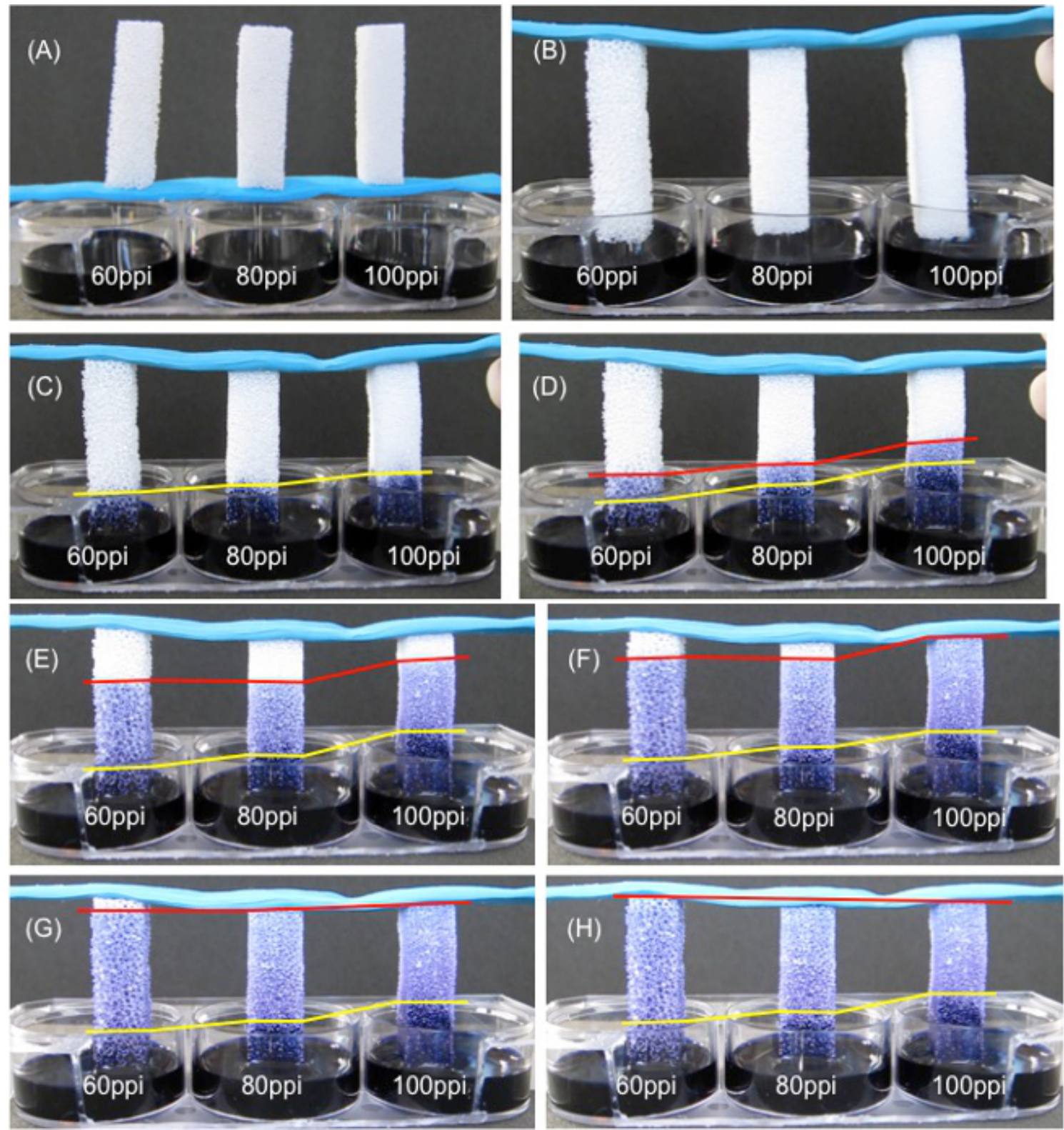

Figure 5. Images showed differences of absorption capabilities of capillary action based on different sizes of primary-pores and micro-channels (primary-pore size refers to the average diameter: $60 \mathrm{ppi} \approx 470 \mu \mathrm{m}, 80 \mathrm{ppi} \approx 320 \mu \mathrm{m}, 100 \mathrm{ppi} \approx 200 \mu \mathrm{m}$ ). The yellow lines represent the capillary action induced by the combination of primary-pores and micro-channels. The red lines represent the capillary action induced by mainly micro-channels exhibited in each trabecula. As shown in (F), the 100 ppi template induced the strongest capillary action, resulting in the complete saturation of the template within $39 \mathrm{sec}$. The $80 \mathrm{ppi}$ and $60 \mathrm{ppi}$ templates were tested thereafter. (B) 0 sec, (C) $0.5 \mathrm{sec}$, (D) $1.5 \mathrm{sec},(E) 17.0 \mathrm{sec},(F) 39.0 \mathrm{sec},(\mathrm{G}) 50.0 \mathrm{sec}$, and (H) $1 \mathrm{~min} 18 \mathrm{sec}$ after immersion. (Template dimension: $1 \mathrm{~cm} \times 1 \mathrm{~cm} \times 4 \mathrm{~cm}$ in height cuboidal). Please click here to view a larger version of this figure. 

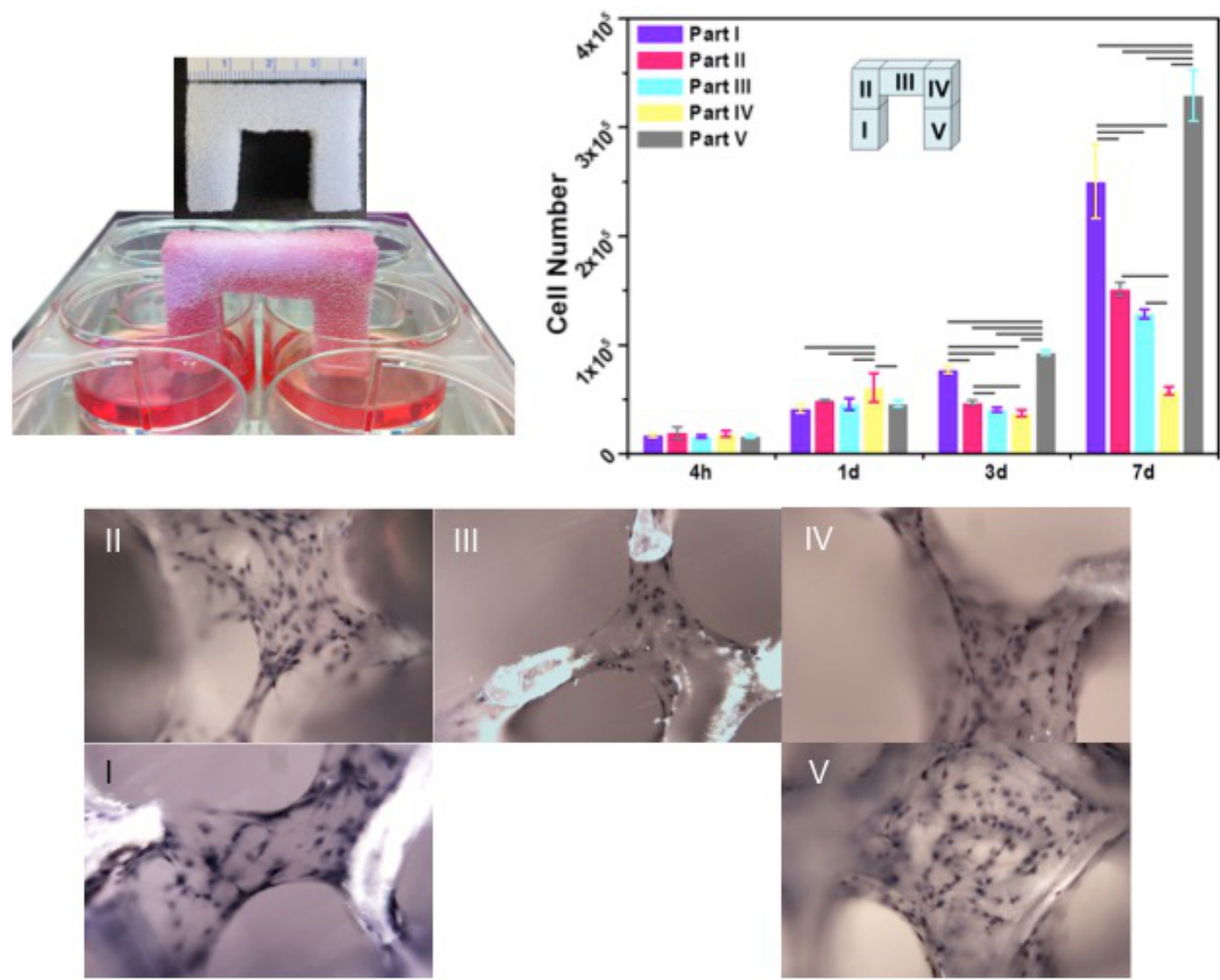

Figure 6. The ingress and immigration of cells from the seeded wells (part I) to unseeded wells (part V) through the biogenic templates induced by capillary action. The initially seeded cells reached the end of the unseeded leg (part V) immediately after full saturation. After 3 days, the confluence of the cells was evident throughout the entire template. After 7 days, spatiotemporal collagen matrix formation occurred within the cell populations (H\&E stain). (Template dimension: $3 \mathrm{~cm}$ in height $\times 4 \mathrm{~cm}$ in length $\times 1 \mathrm{~cm}$ in width). Please click here to view a larger version of this figure.

\section{Discussion}

A multi component template including cells, growth factors, nutrients, etc. is needed for successful bone regeneration and functional restoration of critical-sized large bone defects. Within these factors, anatomically conforming biological properties are essential. To accomplish biological functionality, the template must exhibit biocompatibility, osteoconductivity, mechanical integrity, sufficient surface area, adequate surface texture, and the means for oxygen and nutrient transport. At the cellular level, the following features are especially crucial for functional restoration of massive bone defects: facilitated penetration into template (active recruitment), uniform distribution throughout the template (retention), accelerated proliferation and high viability (habitation). Finally, the subsequent formation of substantial extra cellular matrix and the triggering of gene expression are crucial in essential biological processes such as rapid vascularization and osteogenesis.

Many different types of synthetic substitutes have been proposed to replace auto-/allo- bone grafts. However, the current scaffold organization does not exhibit an internal microenvironment containing micro-channels and nano-pores, and therefore does not actively facilitate cell infiltration, distribution, and inhabitance deep into the synthetic substitutes that are larger than $10 \mathrm{~mm}$. They do not provide physical cues for pioneering cells to efficiently, rapidly, and uniformly migrate deeply into the bone template. Instead, the limited passive recruitment of cells creates an unequally distributed cell populations between the outer and inner areas of the scaffold. This not only exacerbates the initial challenge of the cells reaching the inner core of the template but also hinders nutrient flow and cell communication with the other end of the synthetic substitute. This type of disproportional cell recruitment and inhabitation results in cell death and incomplete bone growth after the scaffold has been implanted into the body ${ }^{14,15}$.

Thus, we have introduced the concept of capillary action as the primary physical cue to address these obstacles. We have thoroughly engineered micro-channels in the BMT to induce the capillary action that will account for the primary dragging force responsibly for actively recruiting cells deep into the BMT.

The PU sponge coating technique presents several unique properties. First, it allows for an easy preparation of well-controlled porous trabecular structures, which themselves depend on the pre-defined template structures (i.e., 80 pore per inch template for $300-400 \mu \mathrm{m}$ ). This is very important for optimizing pore size for osteoblast infiltration ${ }^{15}$. Second, the technique enables the construction of interconnected micro-channels, which account for the significant role of initializing cell relocation ${ }^{11}$. Third, there are almost no limitations when using the PU sponge in terms of creating custom shapes and sizes of the templates. The maker can use a scissor for simple shapes or even computed laser cutting for 
complex geometries. Using these precisely controlled technologies, we created the BMT. HA was selected as the starting material because of its biocompatibility and osteoconductive capacity ${ }^{17}$.

In this study, there are several critical steps that need to be highlighted. During the HA slurry preparation, if the temperature is too high and the stirring speed is too low, the HA slurry will become stuck at bottom edges of the beaker and dry up. After the coating process when blowing out the excess HA slurry, too high of an air pressure can induce cracks on the surface of the BMT. It is important to keep the air pressure relatively low to properly air out the excess HA slurry only. Finally, the second and third steps of the sintering process are most crucial (Heat $1{ }^{\circ} \mathrm{C} / \mathrm{min}$ until $280^{\circ} \mathrm{C}$ and Heat $0.5^{\circ} \mathrm{C} / \mathrm{min}$ until $400^{\circ} \mathrm{C}$ ). In this temperature range, the PU sponge will completely burn out while the HA becomes dense. If this protocol is not closely followed, the BMT will be collapsed or crumbled after sintering.

The BMT described in this study offers several advantages. First, the inter-connected macro-pores (300-400 $\mu \mathrm{m})$ mimic those of human trabecular bone and allows for smooth bone marrow flow. Second, the templates are comprised of micro-channels $(25-50 \mu \mathrm{m})$ within each trabecular septum to accelerate the initial ingress of bone cells via capillary action. As demonstrated using computational simulation ${ }^{13}$, if the template only had $300 \mu \mathrm{m}$ pores (primary pores) and no microchannels, the capillary action would be insufficient for the full saturation of the template with bone marrow. This would especially hold true for large size defects that would require large size templates. Micrometer-sized channels exhibit highly effective fluid absorption, and thus we expected the micro-channels to be primarily responsible for the capillary action in our study. Third, our BMTs have strategically placed nano-pores. Data from the literature indicate that cells are especially sensitive to nanopatterns ${ }^{18,19}$; therefore, we expected the nano-pores on the walls of the micro-channels to play a role in increasing cell attachment. Nano-sized pores $(100-400 \mathrm{~nm})$ on the surface of the trabecular septa allowed immobilized cells to anchor. Overall, the combined effects of these three internal structures resulted in enhanced cell mobilization and adhesion throughout the template. However, there are some limitations of the protocol and the critical steps to fabricate the perfect BMT. For example, there is often a large amount of HA slurry prepared due to the difficulty of keeping a homogeneous viscosity while coating. Also there is a limitation in making templates greater than $5 \mathrm{~cm}^{3}$ in volume due to working time while coating. The coating thickness is critical which varies depending on the maker's techniques.

The findings of our study suggest that the BMT capable of absorbing and retaining cells will offer potential advantages over conventional alloplastic (or synthetic) scaffolds. A prospective study is being considered to verify the benefits of BMT on osteogenesis and/or angiogenesis along with bone-related growth factors. Therefore, we claim that our unique featured BMT scaffold can address the major barriers of insufficient bone marrow infiltration into the synthetic constructs and incomplete bone regeneration in large defects.

The ultimate goal of this study is to simplify the current paradigm of bioengineering in bone reconstruction and functional restoration in criticalsized bony defects by eliminating the need for time-/labor-intensive bone marrow stromal cells isolation and expansion processes. Finally, we aim to utilize anatomically conforming 3D-constructs with micro-channels and nano-pores, which induce rapid cell absorption, homogenous distribution, and inhabitance for reconstruction of bone.

\section{Disclosures}

The authors have nothing to disclose.

\section{Acknowledgements}

The authors have no acknowledgements.

\section{References}

1. Petrie Aronin, E. C., et al. Comparative effects of scaffold pore size, pore volume, and total void volume on cranial bone healing patterns using microsphere-based scaffolds. J Biomed Mater Res A. 89, (3), 632-641 (2009).

2. Guzmán, R., et al. Chitosan scaffolds containing calcium phosphate salts and rhBMP-2: in vitro and in vivo testing for bone tissue regeneration. PLoS One. 9, (2), e87149 (1371).

3. Cha, J. K., et al. Sinus augmentation using BMP-2 in a bovine hydroxyapatite/collagen carrier in dogs. J Clin Periodontol. 41, (1), 86-93 (2014).

4. Karageorgiou, V., Kaplan, D. Porosity of 3D biomaterial scaffolds and osteogenesis. Biomaterials. 26, (27), 5474-5491 (2005).

5. Fisher, M. B., Mauck, R. L. Tissue engineering and regenerative medicine: recent innovations and the transition to translation. Tissue Eng Part B Rev. 19, (1), 1-13 (2013).

6. Manassero, M., et al. Regeneration in Sheep Using Acropora Coral, a Natural Resorbable Scaffold, and Autologous Mesenchymal Stem Cells. Tissue Eng Part A. 19, (13-14), 1554-1563 (2013).

7. Reichert, J. C., et al. A tissue engineering solution for segmental defect regeneration in load-bearing long bones. Sci Transl Med. 4, (141), 141ra93 (2012).

8. Sachlos, E., Czernuszka, J. T. Making Tissue Engineering Scaffolds Work. Review on The Application of Solid Freeform Fabrication Technology to The Production of Tissue Engineering Scaffolds. Eur Cell Mater. 5, 29-40 (2003).

9. Woodard, J. R., et al. The mechanical properties and osteoconductivity of hydroxyapatite bone scaffolds with multi-scale porosity. Biomaterials. 28, (1), 45-54 (2007).

10. Correia, C., et al. Acta Biomater. 8, (7), 2483-2492 (2012).

11. Wang, H., Li, Y., Zuo, Y., Li, J., Ma, S., Cheng, L. Biocompatibility and osteogenesis of biomimetic nano-hydroxyapatite/polyamide composite scaffolds for bone tissue engineering. Biomaterials. 28, (22), 3338-3348 (2007).

12. Oh, D. S., et al. Bone marrow absorption and retention properties of engineered scaffolds with micro-channels and nano-pores for tissue engineering: a proof of concept. Ceram Int. 39, (7), 8401-8410 (2013).

13. Hong, M. H., Kim, Y. H., Ganbat, D., Kim, D. G., Bae, C. S., Oh, D. S. Capillary action: enrichment of retention and habitation of cells via micro-channeled scaffolds for massive bone defect regeneration.J. Mater Sci Mater Med. 25, (8), 1991-2001 (2014). 
14. Volkmer, E., et al. Hypoxia in static and dynamic 3D culture systems for tissue engineering of bone. Tissue Eng. Part A. 14, (8), 1331-1340 (2008).

15. Malda, J., Klein, T. J., Upton, Z. The roles of hypoxia in the in vitro engineering of tissues. Tissue Eng. 13, (9), 2153-2162 (2007).

16. Macchetta, A., Turner, I. G., Bowen, C. R. Fabrication of HA/TCP scaffolds with a graded and porous structure using a camphene-based freeze-casting method. Acta Biomater. 5, (4), 1319-1327 (2009).

17. Cox, S. C., Thornby, J. A., Gibbons, G. J., Williams, M. A., Mallick, K. K. 3D printing of porous hydroxyapatite scaffolds intended for use in bone tissue engineering applications. Mater Sci Eng C Mater Biol Appl. 47, 237-247 (2015).

18. Wan, Y., et al. Adhesion and proliferation of OCT-1 osteoblast-like cells on micro- and nano-scale topography structured poly(l-lactide). Biomaterials. 26, (21), 4453-4459 (2005).

19. Zhao, L., Mei, S., Chu, P. K., Zhang, Y., Wu, Z. The influence of hierarchical hybrid micro/nano-textured titanium surface with titania nanotubes on osteoblast functions. Biomaterials. 31, (19), 5072-5082 (2010). 